\title{
Amniotic fluid embolism: a comprehensive review
}

\author{
Manjusha Viswanathan $^{1 *}$, Viswanathan K. Venkateswaran ${ }^{2}$, Suja Daniel ${ }^{1}$ \\ ${ }^{1}$ Department of Obstetrics \& Gynecology, Sree Gokulam Medical College and Research Foundation, Venjaramoodu, \\ Trivandrum, Kerala, India \\ ${ }^{2}$ Department of Surgery, Medical College Allappuzha, Allappuzha, Kerala, India
}

Received: 29 March 2014

Accepted: 14 April 2014

\section{*Correspondence:}

Dr. Manjusha Viswanathan,

E-mail: manjuvishy94@gmail.com

() 2014 Viswanathan M et al. This is an open-access article distributed under the terms of the Creative Commons Attribution Non-Commercial License, which permits unrestricted non-commercial use, distribution, and reproduction in any medium, provided the original work is properly cited.

\begin{abstract}
Amniotic Fluid Embolism (AFE) is an obstetric catastrophe which occurs in 1 in 8000-80000 deliveries. ${ }^{1}$ It presents with shortness of breath, hypotension, hypoxemia, uterine atony, post-partum hemorrhage, disseminated intravascular coagulation, convulsions, coma and death. Pathophysiology is not clearly understood. It may be due to anaphylactoid like reaction to fetal cells that enter maternal circulation. There are no proven risk factors though a few have been postulated. Treatment is mainly supportive. The corner stone of management is a multi-disciplinary approach with support given to the failing organ systems. The mortality and morbidity due to AFE is very high. Hence prompt diagnosis and effective supportive measures is the key in the management.
\end{abstract}

Keywords: Amniotic fluid embolism (AFE), Disseminated intravascular coagulation (DIC), Hypoxia, Obstetric emergency

\section{INTRODUCTION}

AFE is an obstetric catastrophe where a woman in labor suddenly collapses. It is postulated that amniotic fluid, fetal cells, hair, or other debris enter the maternal circulation, and causes cardio respiratory collapse. Steiner and Luschbaugh described AFE for the first time in 1941 after they found fetal debris in the pulmonary circulation of women who died during labor at post mortem. ${ }^{3}$ They described the condition as peri- partum shock. The entry of amniotic fluid into circulation was first described by Ricardo Meyer in $1926 .{ }^{4}$

Data from the National Amniotic Fluid Embolus Registry describes the process of AFE as similar to anaphylaxis than to embolism. The term anaphylactoid syndrome of pregnancy is now given because fetal tissue or amniotic fluid components are not found in all women who present with signs and symptoms similar to AFE. ${ }^{2,5,6}$ The diagnosis is essentially one of exclusion based on clinical presentation. Other causes of hemodynamic instability should not be neglected. In a critically ill patient, a blood sample obtained by aspiration from pulmonary artery catheter that contains fetal squamous cells is considered suggestive of but not diagnostic of AFE syndrome. ${ }^{3}$

\section{INCIDENCE}

It is difficult to estimate the correct incidence of AFE but it is said to be in the range from 1 in 8000 to 1 in 80000 pregnancies. ${ }^{1}$ The registry for AFE was maintained by Clark et al in USA $^{2}$ and Tuffnel et al. in UK. ${ }^{7}$ The incidence of maternal deaths has drastically reduced in developed countries in the past 30 years due to the advancement in resuscitation methods. Though the mortality has come down, both the maternal and fetal morbidity are still very high. The majority of patients with AFE die within the first hour of onset of symptoms and $85 \%$ of those who survive have permanent neurological deficit. If the fetus is alive at the time of 
embolism, $70 \%$ may survive delivery but $50 \%$ of those neonates who survive will have neurological damage.,

\section{PATHOPHYSIOLOGY}

The pathophysiology of AFE has not been understood well. It is believed that amniotic fluid and fetal cells enter the maternal circulation, and triggers an anaphylactic reaction to the fetal antigens. Fetal material is not always found in the maternal circulation in patients with AFE. All women with amniotic fluid cells in circulation also do not develop features of amniotic fluid embolism

Usually during labor or any other invasive procedure during the antenatal period, amniotic fluid and debris, or some yet unidentified substance, enters the maternal circulation. This triggers a massive anaphylactic reaction, and activation of the complement cascade

Progression occurs in 2 phases. This was described by Clark. ${ }^{9,10}$

Phase I, Pulmonary artery vasospasm with pulmonary hypertension and increased right ventricular pressure causes hypoxia. ${ }^{11}$ This hypoxia causes myocardial capillary damage and pulmonary capillary damage, left heart failure, and acute respiratory distress syndrome. Women who survive these events may enter phase II. Phase 1 may last up to 30 minutes.

Phase II: Hemorrhagic phase. Fatal consumptive coagulopathy may be the initial presentation. This is characterized by massive hemorrhage with uterine atony and DIC; there may be left ventricular failure and pulmonary edema as well. ${ }^{10}$

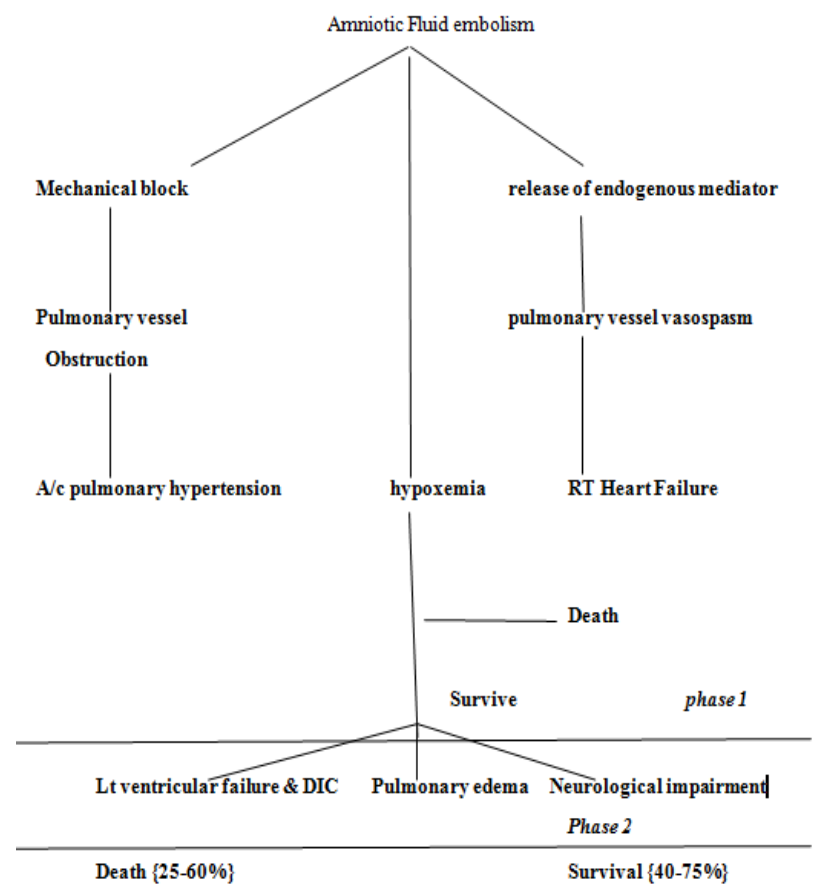

Figure 1: Pathophysiology flow chart.
Table 1: Components of amniotic fluid.

\begin{tabular}{|ll|}
\hline Solution & Suspension \\
\hline Surfactant & Lanugo hair \\
\hline Endothelin & Trophoblasts \\
\hline Leukotrienes C4 \& D4 & Fetal gut mucin \\
\hline IL-1 \& TNF-Alpha & Fetal squamous cells \\
\hline Thromboxane A2 & Bile stained meconium \\
\hline Prostaglandins & Vernix caseosa \\
\hline Arachidonic acid & - \\
\hline Collagen \& tissue factors & - \\
\hline Thromboplastin & - \\
\hline Phospholipase A2 & - \\
\hline
\end{tabular}

\section{CLINICAL FEATURE}

\section{History}

Amniotic Fluid Embolism (AFE) usually occurs during labor. $^{12}$

The syndrome typically occurs during labor or soon after vaginal or caesarean delivery, or during second-trimester dilation and evacuation procedures. In the United States national registry, $70 \%$ of the cases occurred during labor $19 \%$ were recorded during caesarean delivery, and $11 \%$ occurred after vaginal delivery. ${ }^{2}$ All the cases noted during caesarean section had their onset soon after the delivery of the fetus. There is constant relation of AFE to rupture of fetal membranes. Of the women included in the United States National Registry, 78\% had ruptured membranes. Placental abruption was confirmed in $13 \%$ of women. ${ }^{13}$

These findings suggest that certain conditions like artificial rupture of membranes; abruption; hypertonic contractions during induction of labor and dilatation and curettage may permit exposure of fetal tissue to the maternal vasculature and may increase the risk for AFE. ${ }^{10}$

Prodromal symptoms in AFE are sudden chills, shivering, sweating, anxiety, and coughing followed by signs of respiratory distress, shock, cardiovascular collapse, and convulsions. ${ }^{12}$

Respiratory difficulty, evidenced by cyanosis, tachypnea, and bronchospasm, frequently culminates in fulminant pulmonary edema.

Cyanosis, restlessness, convulsions, coma, reflex tachypnea and cardiovascular collapse is due to hypoxia and results from the decreased arterial oxygen saturation. This is heralded by hypotension, tachycardia, and arrhythmia and may end in cardiac arrest.

Convulsions may be an early manifestation of the central nervous system involvement combined with cerebral ischemia and this may lead to coma and death. If the patient survives this initial episode, bleeding occur 
secondary to disseminated intravascular coagulopathy and uterine atony (phase 2). ${ }^{14}$

\section{DIAGNOSIS}

Currently no definitive diagnostic test exists for AFE. The United States and United Kingdom AFE registries recommend the following 4 criteria, all of which must be present to make the diagnosis of AFE. ${ }^{15}$

1. Acute hypotension or cardiac arrest

2. Acute hypoxia

3. Coagulopathy or severe hemorrhage in the absence of other explanations

4. All of these occurring during labor, caesarean section, dilation and evacuation, or within 30 minutes postpartum with no other explanation of findings

The following signs and symptoms are indicative of possible AFE:

1. Hypotension: Blood pressure drops significantly with loss of diastolic measurement.

2. Dyspnea with cough: Labored breathing and tachypnea occur.

3. Cyanosis: As hypoxia/hypoxemia progresses, circum oral and peripheral cyanosis occurs and changes in mucous membranes may also be seen.

4. Pulmonary edema: This is usually identified on chest radiograph.

5. Cardiac arrest.

6. Seizure: Generalized tonic clonic seizures are seen in $50 \%$ of patients.

7. Fetal bradycardia: In response to the hypoxic insult, fetal heart rate may drop to less than 110 beats per minute (bpm). If this drop lasts for 10 minutes or more, it is a bradycardia. A rate of $60 \mathrm{bpm}$ or less over 3-5 minutes may indicate a terminal bradycardia. Immediate delivery of the fetus is indicated.

8. Uterine atony: Uterine atony usually results in excessive bleeding after delivery. Failure of the uterus to become firm with bimanual massage is diagnostic.

9. Coagulopathy or severe hemorrhage in the absence of other explanation (DIC occurs in $83 \%$ of patients).

10. Altered mental status/confusion/agitation.
Table 2: Signs and symptoms of AFE.

\begin{tabular}{|l|}
\hline Sign and symptoms \\
\hline Hypotension* \\
\hline Chills \\
\hline Headache \\
\hline Nausea \\
\hline Vomiting \\
\hline Hypoxia* \\
\hline DIC* \\
\hline Seizure \\
\hline Altered mental status* \\
\hline Fever \\
\hline Chest pain \\
\hline Bronchospasm* \\
\hline Uterine atony* \\
\hline Fetal distress* \\
\hline *-present in $80-100 \%$ of affected women \\
\hline
\end{tabular}

\section{Lab tests ${ }^{5}$}

Arterial Blood Gas (ABG) levels: changes are consistent with hypoxia/hypoxemia.

Decreased $\mathrm{pH}$ levels (reference range is 7.40-7.45)

Decreased $\mathrm{PO}_{2}$ levels (reference range is 104-108 mm $\mathrm{Hg}$ )

Increased $\mathrm{PCO}_{2}$ levels (reference range is $27-32 \mathrm{~mm} \mathrm{Hg}$ )

Base excess increased

1. Hematological tests: Complete blood count

Hemoglobin and hematocrit levels will be within reference ranges.

Thrombocytopenia is rare.

Platelet transfusion is given at $1-3 \mathrm{U} / 10 \mathrm{~kg} /$ day when

- $\quad$ Platelets are less than $20000 / \mu \mathrm{L}$

- $\quad$ Bleeding occurs and platelets are $20,000-50,000 / \mu \mathrm{L}$

2. Prothrombin time

Prothrombin Time (PT) is prolonged because clotting factors are used up. Intervention is required when the PT is 1.5 times the control value. Fresh frozen plasma (FFP) is given to normalize the PT.

3. Activated partial thromboplastin time (aPTT): This may be within normal ranges or shortened. 
4. Fibrinogen level. If fibrinogen level is less than 100 $\mathrm{mg} / \mathrm{dL}$, administer cryoprecipitate. Each unit of cryoprecipitate raises the fibrinogen level $10 \mathrm{mg} / \mathrm{dL}$.

5. Blood grouping and $\mathrm{RH}$ typing done for cross matching and blood transfusion given when required.

6. Chest $X$ ray may show features of pulmonary embolism.

7. A 12-lead ECG may show tachycardia, ST segment and $\mathrm{T}$-wave changes, and findings consistent with right ventricle strain.

Table 3: Lab investigations.

\begin{tabular}{|ll|}
\hline Non specific & Specific \\
\hline Complete blood picture & - \\
\hline $\begin{array}{l}\text { Coagulation parameter: } \\
\text { FDP, fibrinogen }\end{array}$ & - \\
\hline Arterial blood gas & Serum tryptase \\
\hline Chest X ray & Tn Antigen \\
\hline ECG & Serum Sialye \\
\hline ECHO & Zinc coproporphyrin \\
\hline
\end{tabular}

The Sialyl Tn antigen test was described by Kobayashi and colleagues, who showed that monoclonal antibodies TKH-2, MA54, B72.3, and CC49 react with meconium and amniotic fluid-derived mucin. ${ }^{16}$ TKH-2 has the ability to detect the lowest concentration of the antigen.

Sialyl is a mucin-type glycoprotein that originates in fetal and adult intestinal and respiratory tracts. It is a major component in meconium (10\% by weight) and is also present in clear amniotic fluid. ${ }^{16}$

Using a sensitive anti-mucin antibody TKH-2, the authors found no difference in the serum levels of Sialyl Tn antigen in pregnant patients throughout gestation or in early post-partum period when compared with nonpregnant controls.

In contrast, the antigen concentrations were significantly elevated in patients with AFE. The monoclonal antibody TKAH-2 may eventually prove useful in rapid, noninvasive diagnosis of AFE.

Plasma concentration of zinc coproporphyrin, a characteristic component of meconium, has shown to be greater in patients with suspected AFE. At present, clinical experience with the Sialyl Tn antigen and zinc coproporphyrin is limited and further studies are needed to assess the reliability and utility of these tests

\section{DIFFERENTIAL DIAGNOSIS ${ }^{11}$}

As we have mentioned, amniotic fluid embolism is a diagnosis of exclusion. Hence the knowledge of differential diagnosis is very important. ${ }^{17}$
1. Thrombotic pulmonary embolism - This is associated with chest pain. It occurs in the post-partum period and there will be definite evidence of venous thrombosis $^{18}$

2. Eclampsia - Convulsions may be common to both. But shock is seen in AFE. Hypertension proteinuria and convulsions are pathognomonic of eclampsia ${ }^{19}$

3. Air embolism - Auscultation will reveal water wheel murmur over pericardium. There will be associated chest pain in both ${ }^{19}$

4. Acute left heart failure- Seen in patients with previous history of heart disease. There will be associated murmur. ECHO will clinch the diagnosis

5. Drug reaction to anesthetic drugs

6. Cerebrovascular accidents (CVA)-In CVA there will be no cyanosis hypotension or pulmonary edema

7. Aspiration of gastric contents

8. Hemorrhagic shock in an obstetric patient associated with ruptured uterus, uterine inversion, abruptio placenta, and placenta praevia

\section{MANAGEMENT}

The key factors in the management of AFE are early recognition, prompt resuscitation, and delivery of fetus. Approach should be multidisciplinary involving anesthetists, obstetricians, hematologists and intensivists.

Treatment is supportive. $^{5}$

- Administer oxygen to maintain normal saturation. Intubate if necessary.

- Initiate cardiopulmonary resuscitation (CPR) if the patient has cardiac arrest.

- Treat hypotension with crystalloid and blood products. Use pressor agents when necessary.

- Consider pulmonary artery catheterization in patients who are hemodynamically unstable.

- Continuously monitor the fetus and ensure prompt delivery.

- Treat coagulopathy.

FFP for a prolonged PT

Cryoprecipitate for a fibrinogen level less than 100 $\mathrm{mg} / \mathrm{dL}$, 
Transfuse platelets for platelet counts less than $20,000 / \mu \mathrm{L}$

Table 4: Management of AFE symptomatic depending on severity. ${ }^{20}$

\begin{tabular}{|ll|}
\hline Maintenance of oxygenation & Supplement oxygen \\
\hline- & Tracheal intubation \\
\hline- & Ventilatory support \\
\hline Circulatory support & Volume maintenance \\
\hline- & Inotropes \\
\hline- & After load reduction \\
\hline $\begin{array}{l}\text { Cardio pulmonary resuscitation } \\
\text { protocol }\end{array}$ & - \\
\hline Delivery of fetus & \\
\hline Correction of coagulopathy & Fresh frozen plasma \\
\hline- & Packed cell RBC \\
\hline- & Platelet rich plasma \\
\hline- & Cryoprecipitate \\
\hline
\end{tabular}

\section{CONCLUSION}

Amniotic fluid embolism syndrome is an infrequent, unpredictable, and catastrophic complication of pregnancy.

It is impossible to predict high risk patients for Amniotic fluid embolism.

Diagnosis is based on a spectrum of clinical signs and symptoms and by exclusion of other causes that produce such symptoms.

Most cases of AFE are associated with high maternal and fetal morbidity and mortality, regardless of the quality of care rendered.

Improved understanding of the pathophysiology of AFE may lead to the development of preventive measures and more effective and specific treatment. Although there are many new developments with respect to the understanding of the disease, amniotic fluid embolism continues to be a catastrophic illness requiring a high index of suspicion, a multidisciplinary approach and rapid resuscitation efforts in order to have a desirable clinical outcome.

We must develop national and international registries and encourage collaboration between research centers. Without a specific method to confirm the diagnosis and registries to collect the data, our understanding of the natural history, etiology and treatment will continue to be hampered.

Funding: No funding sources Conflict of interest: None declared

Ethical approval: Not required

\section{REFERENCES}

1. Morgan M. Amniotic fluid embolism. Anesthesia. 1979;30:20-6.

2. Clarke SL, Hankins G, Dudley DA, Dildy GA, Porter TF. Amniotic fluid embolism: analysis of the national registry. Am J Obstet Gynecol. 1995;172:1158-67.

3. Steiner PE, Lushbaugh CC. Maternal pulmonary embolism by fluid as a cause of obstetric shock and unexpected deaths in obstetrics. J Am Med Assoc. 1941;117:1245-54.

4. Meyer JR. Embolia pulmonar amnio-caseosa. Braz Med. 1926;2:301-3.

5. Porter TF. Amniotic fluid embolism: analysis of the national registry. Am J Obstet Gynecol. 1995;172:1158-67.

6. Hankikns GD, Snyder RR, Clarke SL, Schwartz L, Patterson WR, Clifford A. Acute hemodynamic and respiratory effects of amniotic fluid embolism in the pregnant goat model. Am J Obstet Gynecol. 1993;168:1113-30.

7. Tuffnell DJ. United Kingdom amniotic fluid embolism register. BJOG. 2005;112:1625-9.

8. Warden MR. Amniotic fluid amnio as possible factor in etiology of eclampsia. Am J Obstet Gynecol. 1927;14:292-300.

9. Clark SL. New concepts of amniotic fluid embolism: a review. Obstet Gynecol Surv. 1990;45:360-8.

10. Gei G, Hankins GD. Amniotic fluid embolism: an update. Contemp Obstet/Gynecol. 2000;45:53-62.

11. Reeves WC, Demers LM, Wood MA, Skarlatos S, Copenhaver G, Whitesell $\mathrm{L}$ et al. The release of thromboxane A2 and prostacyclin following experimental acute pulmonary embolism. Prostagland Leukot Med. 1983;11:1-10.

12. Hassart TH, Essed GG. Amniotic fluid embolism after transabdominal amniocentesis. Eur J Obstet Gynecol Reprod Biol. 1983;16:25-30.

13. Locksmith GJ. Amniotic fluid embolism. Obstet Gynecol C1 N Am. 1999;26:435-44.

14. A. Rudra, Schalter Jee, J. Mitra, Sengupta S. Amniotic fluid embolism. J Indian Soc Crit Care Med. 2009;13(3):129-35.

15. Moore Lisa E, Smith Carl V. Amniotic fluid embolism, 2012. Available at: http://www.medscape.com. Accessed 11 November 2013.

16. Kobayashi $\mathrm{H}$, Ohi $\mathrm{H}$, Tera OT. A simple noninvasive sensitive method of diagnosis of amniotic fluid embolism by monoclonal antibody. Am J Obstet Gynecol. 1993;16B:848-53.

17. Sperry K. Landmark perspective: amniotic embolism. To understand an enigma. J Am Med Assoc. 1986;255:2183-6.

18. Karetzky M, Ramirez M. Acute respiratory failure in pregnancy: an analysis of 19 cases. Med. 1998;77:71-9. 
19. Gogola J, Hankins GD. Amniotic fluid embolism in progress: a management dilemma. Am J Perinatol. 1998;15:491-3.

20. Maher JE, Wenstorm KD, Hauth JC, Meis PJ. Amniotic fluid embolism after saline amnioinfusion: two cases and a review of the literature. Obstet Gynecol. 1994;83:851-4.

DOI: $10.5455 / 2320-1770 . i j r \operatorname{cog} 20140603$

Cite this article as: Viswanathan M, Viswanathan KV, Daniel S. Amniotic fluid embolism: a comprehensive review. Int J Reprod Contracept Obstet Gynecol 2014;3:304-9. 